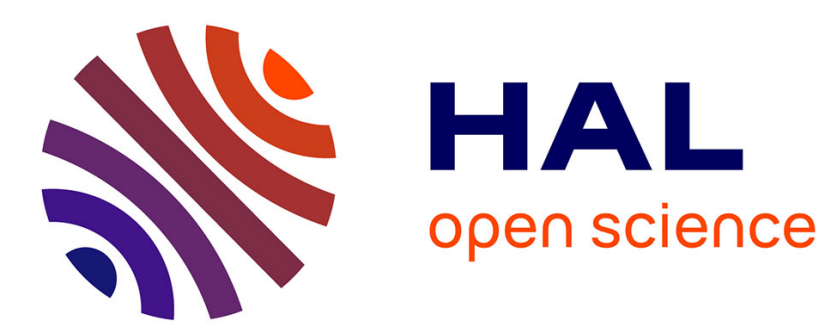

\title{
ECG vs. Single-Antenna System for Heartbeat Activity Detection
}

Dany Obeid, Gheorghe Zaharia, Sawsan Sadek, Ghaïs El Zein

\section{To cite this version:}

Dany Obeid, Gheorghe Zaharia, Sawsan Sadek, Ghaïs El Zein. ECG vs. Single-Antenna System for Heartbeat Activity Detection. ISABEL 2011, Oct 2011, Barcelone, Spain. 10.1145/2093698.2093838 . hal-00671196

\section{HAL Id: hal-00671196 https://hal.science/hal-00671196}

Submitted on 16 Feb 2012

HAL is a multi-disciplinary open access archive for the deposit and dissemination of scientific research documents, whether they are published or not. The documents may come from teaching and research institutions in France or abroad, or from public or private research centers.
L'archive ouverte pluridisciplinaire HAL, est destinée au dépôt et à la diffusion de documents scientifiques de niveau recherche, publiés ou non, émanant des établissements d'enseignement et de recherche français ou étrangers, des laboratoires publics ou privés. 


\title{
ECG vs. Single-Antenna System for Heartbeat Activity Detection
}

\author{
Dany Obeid ${ }^{1}$, Gheorghe Zaharia ${ }^{2}$, Sawsan Sadek ${ }^{3}$, Ghais El Zein ${ }^{2}$ \\ ${ }^{1}$ Kaptalia Monitoring, Prisme 2, PIBS, 56000 Vannes, France \\ ${ }^{2}$ IETR UMR CNRS 6164 - INSA, Rennes, France \\ ${ }^{3}$ Lebanese University, IUT, Saida, Lebanon \\ d.obeid@kaptalia.com
}

\begin{abstract}
This paper presents a single antenna Doppler system for contactless heartbeat monitoring. The proposed system, based on using a vector network analyzer, is tested at $16 \mathrm{GHz}$ frequency for different transmitted power levels between 0 and $-25 \mathrm{dBm}$. Both heartbeat rate and heart rate variability are extracted from the signals obtained with the Doppler system and compared to simultaneous ECG signals.
\end{abstract}

\section{Keywords}

Doppler radar; heartbeat rate; heart rate variability; touch-less detection.

\section{INTRODUCTION}

Affixed electrodes for traditional electrocardiograms are perturbing for long-duration home monitoring, as well as for patients with conditions such as burn victims or newly born infants. Therefore, it is convenient to use a microwave Doppler radar for such applications. These include home health care applications, urgent conditions, and hospital needs. In addition, a touch-less technique can be used to detect life signs for people under rubble [1].

According to Doppler theory [2], a person's chest reflects the transmitted signal with its phase modulated by the time-varying position of the chest. The reflected signal contains information about the chest displacement due to heartbeat and respiration. However, while holding breath, the reflected signal depends on the chest displacement due to heartbeat alone. At rest, the variation of the chest displacement, caused by respiration, is between 4 and $12 \mathrm{~mm}$ [3], and the chest displacement due to heartbeat alone ranges between 0.2 and $0.5 \mathrm{~mm} \mathrm{[4].} \mathrm{The}$ respiration rate corresponds to a frequency that varies between 0.1 and $0.3 \mathrm{~Hz}$, while the heartbeat rate (HR) corresponds to a frequency that varies between 1 and $3 \mathrm{~Hz}$ [5].

Previous works tended to detect life signs $[6,7]$, respiration rates and heartbeat rates, using fixed frequency and fixed power of the transmitted signal. Direct-conversion Doppler radars, operating at 1.6 GHz and $2.4 \mathrm{GHz}$, have been integrated in $0.25 \mu \mathrm{m}$ CMOS and BiCMOS technologies [8]. Heart and respiration activities were detected using a modified Wireless Local Area Network PCMCIA card, and a module combining the transmitted and reflected signals [9]. Other systems operating in the Ka-Band were described in [10] using a low power double-sideband transmission signal. Similarly, quadrature demodulation architecture is used to detect vital signs from distance [11]. A new study showing the possibility of detecting the presence of a person through a wall using Ultra-Wideband (UWB) radar is presented in [12]. Some experiments are performed for the detection of life signs using the $4-7 \mathrm{GHz}$ band with $1 \mathrm{~mW}$ power and around $7 \mathrm{~dB}$ antenna gain [13]. A recent study describes a system operating at $94 \mathrm{GHz}$ that is able to detect the heart and the respiration activities of stationary subjects [14].

Our previous work tended to demonstrate the possibility of detecting the heartbeat activity with two-antenna microwave system [15], for different operational frequencies and several transmitted powers. In this paper, a single-antenna microwave system for heartbeat detection is proposed. The proposed system, tested for one frequency and several transmitted powers, is validated with an electrocardiogram (ECG) signal.

In addition to the installation simplicity, the proposed system has the ability of tuning both frequency and power. As the transmission of a signal with minimum power would be safer for both patient and medical staff, measurements are performed for several transmitted power levels between 0 and $-25 \mathrm{dBm}$. Both heartbeat rate (HR) and heart rate variability (HRV) are extracted and compared to the values obtained by the ECG. The rest of the paper is organized as follows: Section 2 presents background information, the proposed system with its two versions, and a smoothing technique. Section 3 presents the heartbeat signals obtained using the proposed system. Section 4 states the results of extracting the heartbeat rate and the heart rate variability from the phase of $\mathrm{S}_{11}$. Section 5 concludes the work.

\section{MEASUREMENT SETUP}

The chest displacement varies between $4 \mathrm{~mm}$ and $12 \mathrm{~mm}$ due to respiration, while it ranges between $0.2 \mathrm{~mm}$ and $0.5 \mathrm{~mm}$ due to heart beatings. The measurement of this small displacement is the objective of this work. The proposed system detects the heartbeat activity upon the detection of the phase variation of parameters $\mathrm{S}_{11}$ measured by a vector network analyzer (VNA). The phase variation is directly proportional to the chest displacement and indirectly proportional to the wavelength of the transmitted signal. The relation between the chest displacement $\Delta x(t)$ and the phase variation $\Delta \theta(t)$ is:

$$
\Delta \theta(t)=\frac{4 \pi \Delta x(t)}{\lambda}
$$

where $\lambda$ is the wavelength of the transmitted signal. Measurements were performed while holding the breath for duration of 15 seconds. This duration can vary with few milliseconds in order to sustain synchronization between the VNA and the ECG. The number of points taken for the signals measured with the VNA is 20000. The use of a VNA accommodates a quick and simple installation process. Figure 1 describes the proposed system. 


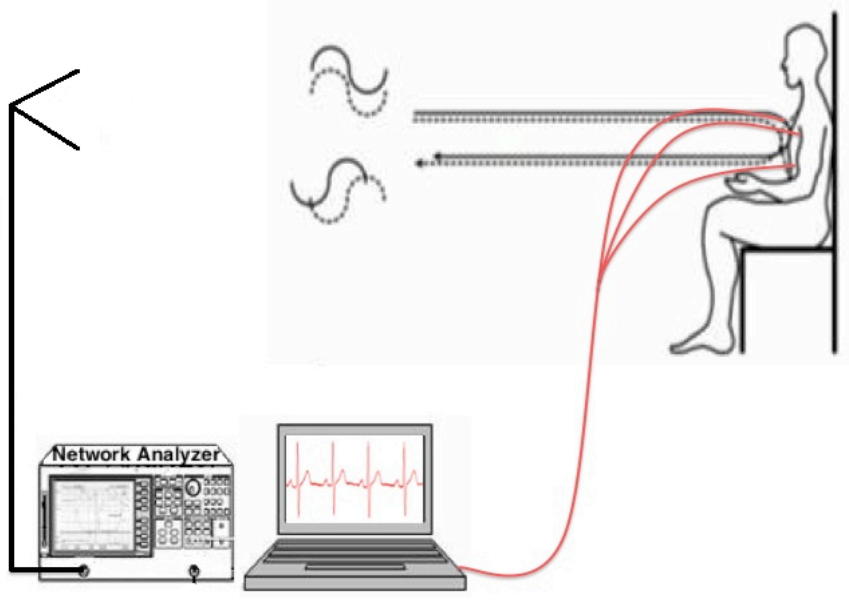

Figure 1. Measurement system: single-antenna Doppler radar system vs. an electrocardiogram.

The operational frequency used in these measurements is $16 \mathrm{GHz}$. The choice of this frequency is made according to two reasons. The first one is to obtain higher phase variation as it is directly proportional to the frequency, and the second reason is due to the equipment's limits $(2-16 \mathrm{GHz}$ for the antenna).

An extension of the system using two antennas and operating at $60 \mathrm{GHz}$ is described in $[15,16]$. The measurements procedure starts by sending a continuous wave signal at the desired frequency. The signal is generated by the VNA and driven to the antenna, which is directed toward the person's chest. The transmitted signal is reflected off the person chest and received by the same antenna. The received signal is used to compute the phase variation of $\mathrm{S}_{11}$. This variation is due to the chest displacement. Hence, it contains information about the cardiopulmonary signals when breathing normally, and about the heartbeat signal when holding the breath. Since the heartbeat rate is based on the detection of the signal peaks, a smoothing method is applied in order to reduce the number of surrounding peaks. This method is based on the Newton relation, which is described in $[16,17]$.

\section{HEARTBEAT SIGNALS: ECG VS. $S_{11}$}

Measurements are performed for several transmitted powers between 0 and $-25 \mathrm{dBm}$, and for a distance of $1 \mathrm{~m}$ to the person.

Figure 2 (a) shows the heartbeat signal detected using an ECG, while Figure 2 (b) shows the phase variation of $S_{11}$ due to the heartbeat activity. These two signals are obtained simultaneously for the same patient. Figure 2 (c) shows the phase variation after applying the smoothing technique.

Beside that the heartbeat signal detected with an ECG represents the electrical activity of the heart, the goal of the microwave Doppler system is to measure the heartbeat rate and the heart rate variability; these correspond respectively to the average of the R$\mathrm{R}$ intervals and its variation. Figure 3 shows an exemplary output for an ECG signal. Figure 4 shows the heartbeat signals that correspond to the phase of $\mathrm{S}_{11}$ detected by the proposed microwave system for several power levels of the transmitted signal: $0 \mathrm{dBm}$ (a), $-5 \mathrm{dBm}$ (b), $-10 \mathrm{dBm}$ (c), $-15 \mathrm{dBm}$ (d), -20 $\mathrm{dBm}(\mathrm{e})$, and $-25 \mathrm{dBm}(\mathrm{f})$. It can be noticed that as the power decreases, the signal-to-noise ratio (SNR) decreases. However, the peaks of the signals can still be detected. The effect of smoothing these signals is shown in Figure 5. Note that y-axis of Figures 2 $(b, c)$ and Figures $4(b, c)$ represent the phase in degrees, while the $y$-axis of Figures 2 (a) and Figures 4 (a) stand for the ECG signal represented by 8 bits digital values.
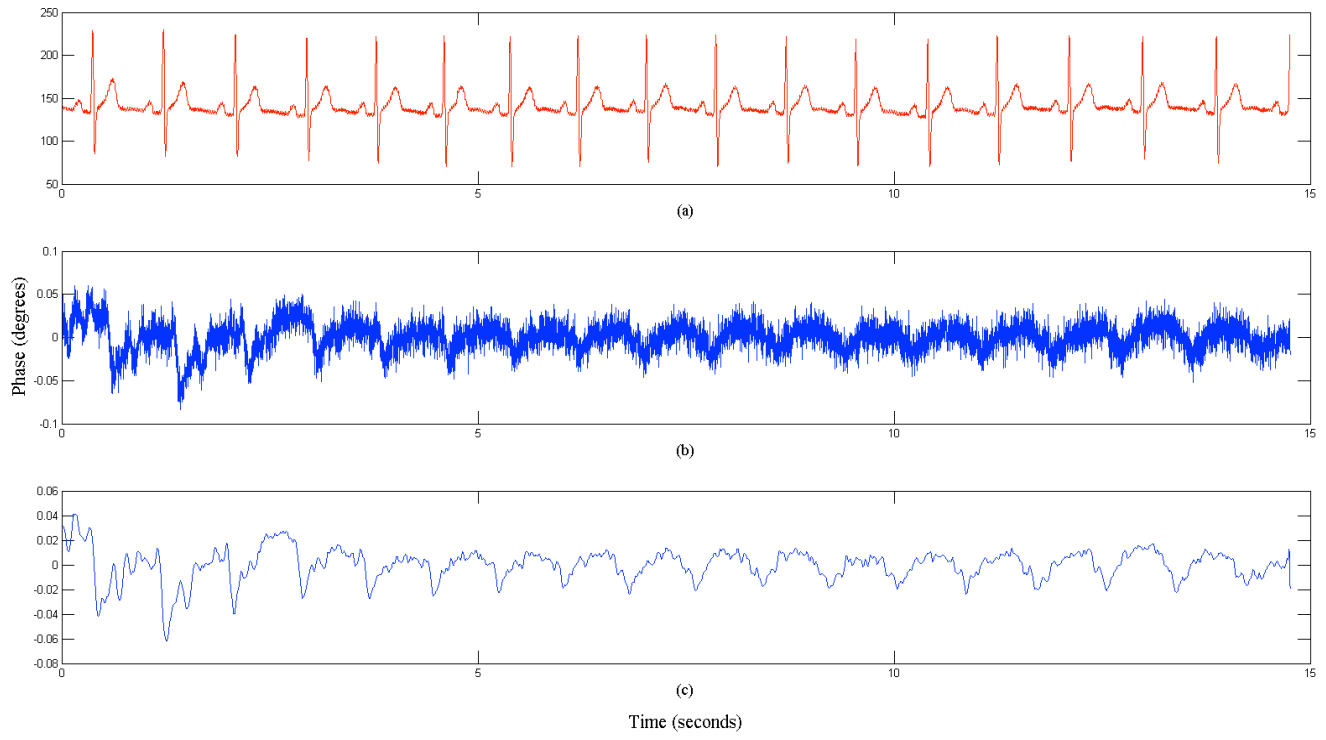

Figure 2. Heartbeat signal detected with the proposed system (b and c) vs. the ECG signal (a). 


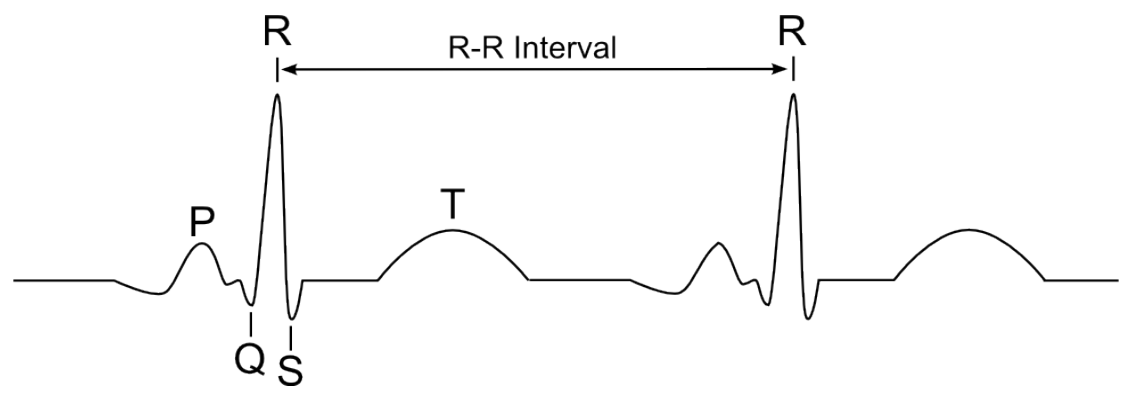

Figure 3. R-R interval for an ECG exemplary output signal.
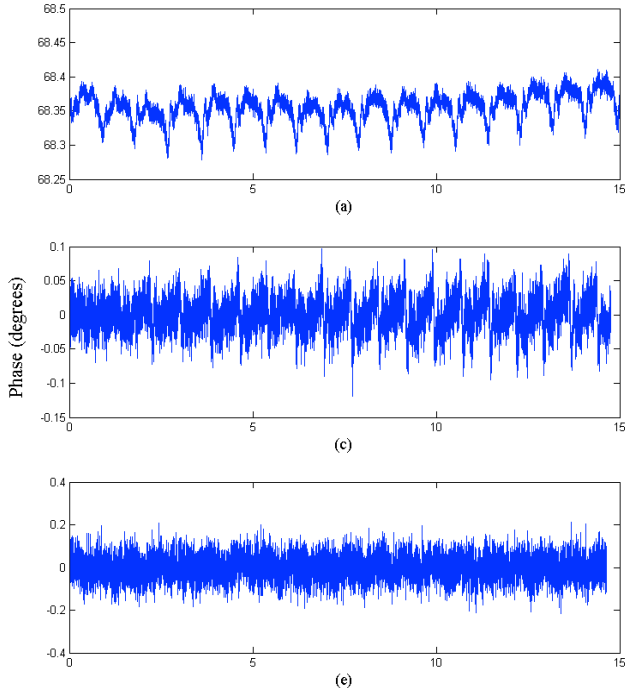

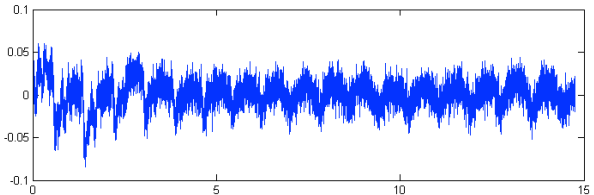

(b)

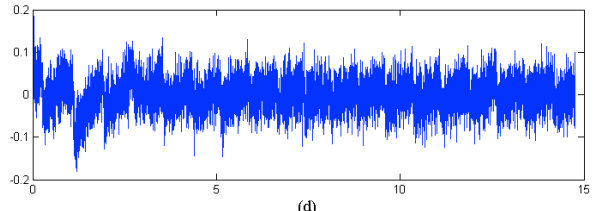

(d)

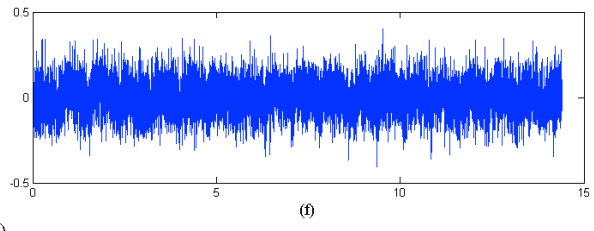

Figure 4. Heartbeat signals detected at $16 \mathrm{GHz}$ for the following transmitted power levels: $0 \mathrm{dBm}(\mathrm{a}),-5 \mathrm{dBm}$ (b), $-10 \mathrm{dBm}$ (c), $-15 \mathrm{dBm}$ (d), $-20 \mathrm{dBm}$ (e), and $-25 \mathrm{dBm}$ (f).
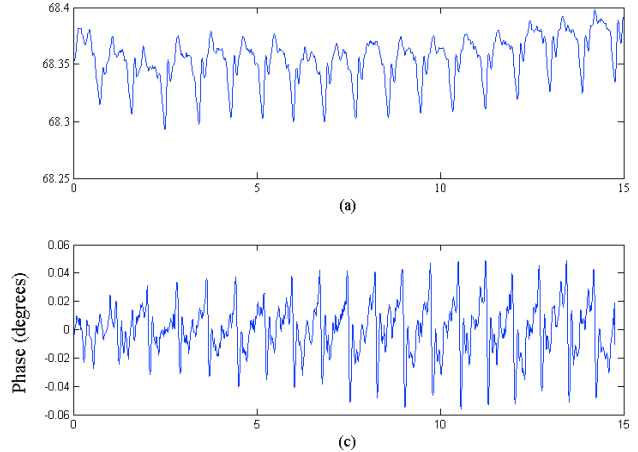

(c)

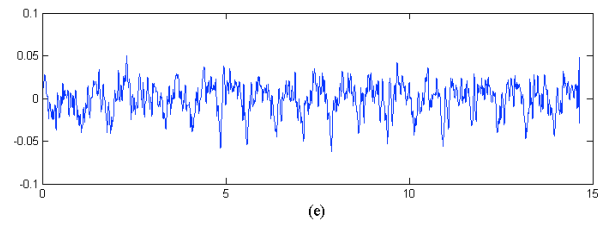

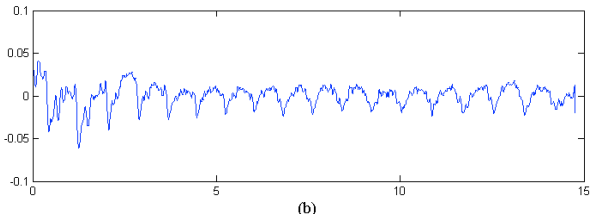

(b)
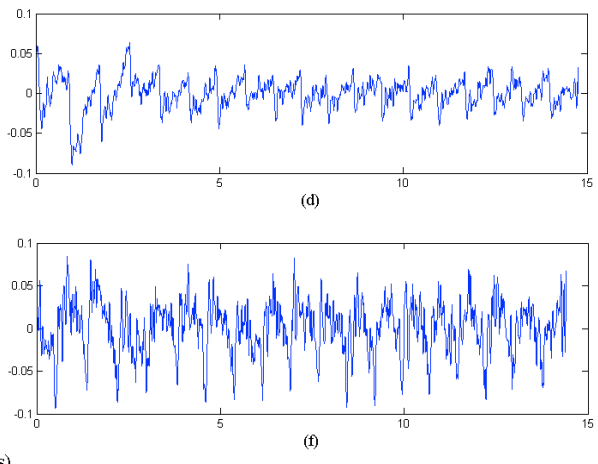

Figure 5. Heartbeat signals detected at $16 \mathrm{GHz}$ for several transmitted power levels after applying the smoothing technique: $0 \mathrm{dBm}(\mathrm{a}),-5 \mathrm{dBm}(\mathrm{b}),-10 \mathrm{dBm}(\mathrm{c}),-15 \mathrm{dBm}(\mathrm{d}),-20 \mathrm{dBm}$ (e), and $-25 \mathrm{dBm}$ (f). 


\section{RESULTS: HR AND HRV}

Previous works tended to extract the average heartbeat rate over a specific window of time. This does not provide information about the time-variation of the HR, i.e. the HRV. Thus, a peak detection technique is required to track the peaks of the signal. In this work, the heartbeat rate and the HRV of the signals detected for different power levels are extracted. Values obtained from $S_{11}$ parameter, for original and smoothed signals, are compared to the HR and the HRV obtained from the ECG reference signal. Figure 6 shows the HR relative error of the Doppler radar system, for the phase of $S_{11}$ with respect to the reference ECG signal. The effects of smoothing the signal are also shown in this figure.

Obtained results show that the phase of $\mathrm{S}_{11}$ can detect the heartbeat signals with relative errors around $1.5 \%$ at $0 \mathrm{dBm}$. The HR relative error changes between $1.5 \%$ and $26 \%$ for transmitted power between 0 and $-25 \mathrm{dBm}$ respectively. The smoothing technique changes these values to $2 \%$ and $12 \%$ respectively.

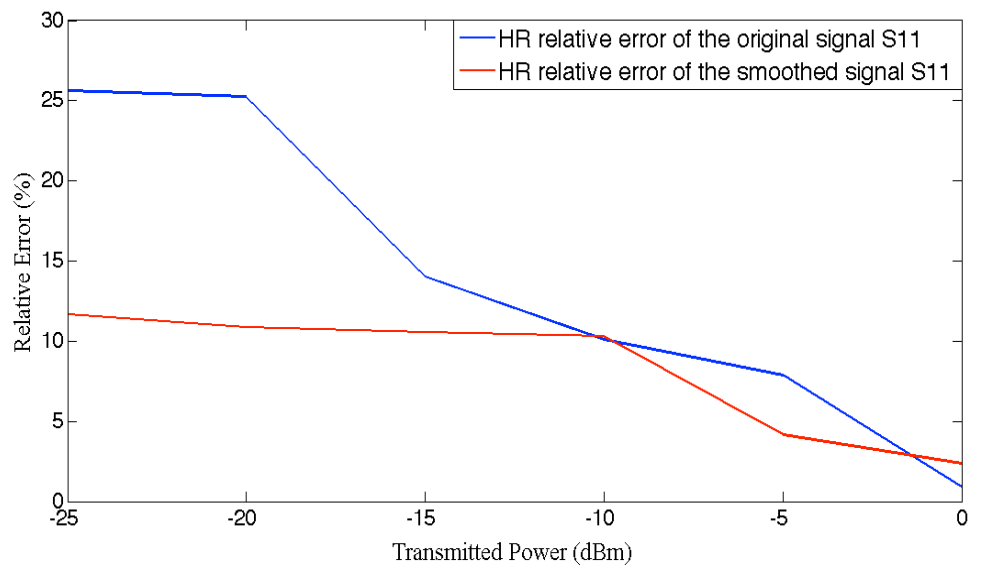

Figure 6. Heartbeat rate relative errors for the original and the smoothed signals obtained from $S_{11}$ at $16 \mathrm{GHz}$.

The HRV is a measure of the beat-to-beat variations ( $R-R$ interval for the ECG signal). HRV is regarded as an activity indicator of autonomic regulation of circulatory function [18].

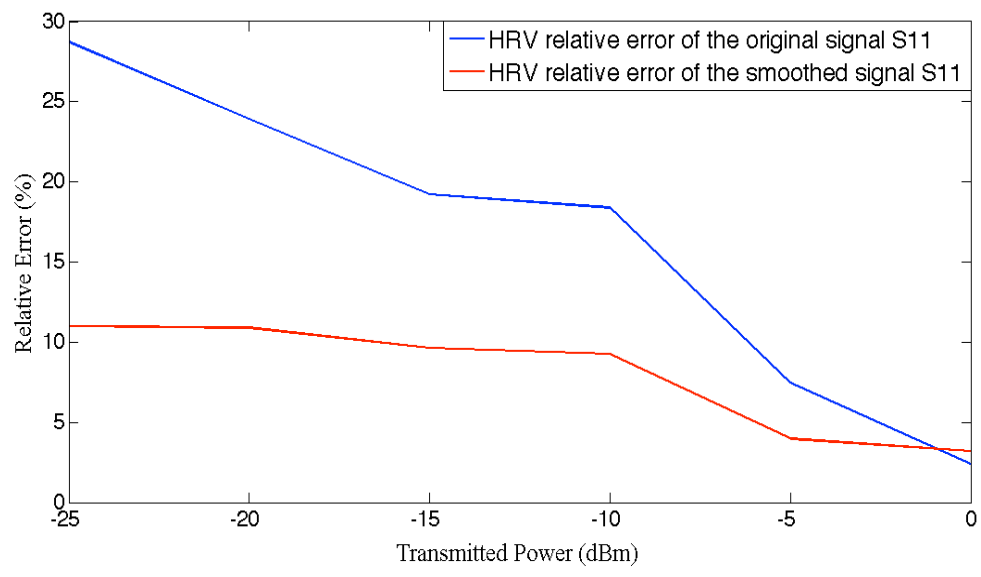

Figure 7. Heart rate variability relative errors for the original and the smoothed signals obtained from $S_{11}$ at $16 \mathrm{GHz}$.
The extraction of the heartbeat rate requires the use of simple averaging over a specific window. However, this lacks providing the time-variation of the heartbeat rate. On the other hand, the extraction of the heart rate variability requires peak-to-peak detection. Hence, a peak detection method (PDM) is used. This technique is based on tracking the maximum value in a sliding window, which is greater than a specific threshold. Figure 7 shows the HRV relative error of the Doppler radar system, for the phase of $S_{11}$ with respect to the reference ECG signal. The effects of smoothing the signal are shown as well. The obtained results show the possibility of detecting the peaks of the signal with high accuracy. The HRV relative error changes between $2.5 \%$ and $28 \%$ for transmitted power between 0 and $-25 \mathrm{dBm}$. However, smoothing the signal changes the HRV error to the $3-11 \%$ interval.

\section{CONCLUSION}

A single-antenna microwave system is proposed in order to detect the heart beatings of a person from a distance of 1 meter. The phase variations of $S_{11}$ obtained with a VNA due to the heart activity are extracted and compared to a simultaneous ECG signal. Obtained results show the possibility of detecting the heartbeat activity and allow extracting the heartbeat rate and the heart rate variability.

Measurements are performed at $16 \mathrm{GHz}$ and for several transmitted power levels between 0 and $-25 \mathrm{dBm}$. Beside its installation simplicity, the VNA provides the opportunity of testing several transmitted powers. Determining the minimum possible transmitted power would be safer for the patient and the medical staff. A smoothing technique is applied to the signal where high accuracy is observed in extracting the HR and the HRV.

Future work will focus on performing measurements for several operational frequencies. This helps determining the optimum operational frequency for the minimum transmitted power.

\section{ACKNOWLEDGMENTS}

The authors acknowledge CEDRE (project reference number: 08SciF6/L4), AUF (project reference number: G3-110/1649), and "Région Bretagne" for partially funding this work.

\section{REFERENCES}

[1] H-R. Chuang, Y. Chen, and K.-M. Chen, "Automatic cluttercanceler for microwave life-detection systems," IEEE Transactions on Instrumentation and Measurement, vol. 40, no. 4, pp. 747 -750, Aug. 1991.

[2] J. C. Lin, "Microwave sensing of physiological movement and volume change: A review," Bioelectromagnetics (1992), vol. 13 , pp. 557-565.

[3] A. De Groote, M. Wantier, G. Cheron, M. Estenne, and M. Paiva, "Chest wall motion during tidal breathing," Journal of Applied Physiology (1997), vol. 83, no. 5, pp. 1531-1537.

[4] G. Ramachandran and M. Singh, "Three-dimensional reconstruction of cardiac displacement patterns on the chest wall during the P, QRS, and T-segments of the ECG by laser speckle interferometry," Medical and Biological Engineering and Computing (1989), vol. 27, no. 5, pp. 525-530.

[5] F. Mohammad-Zahed, F. Taghibakhsh and B. Kaminska, "Contactless Heart Monitoring," 2007 IEEE, Session 33. Biomedical Signal Processing-I, pp. 583-585.

[6] K. M. Chen, Y. Huang, J. Zhang, and A. Norman, "Microwave life-detection systems for searching human 
subjects under earthquake rubble and behind barrier", IEEE Trans. Biomed. Eng. Jan. 2000, vol. 47, no. 1, pp. 105-114.

[7] A. D. Droitcour, V. M. Lubecke, J. Lin, and O. BoricLubecke, "A microwave radio for Doppler radar sensing of vital signs," in IEEE MTT-S Int. Microw. Symp. Dig., May 2001, pp. 175-178.

[8] A. D. Droitcour, O. Boric-Lubecke, V. M. Lubecke, and J. Lin, "0.25 $\mu \mathrm{m}$ CMOS and BiCMOS single chip direct conversion Doppler radars for remote sensing of vital signs," in IEEE Int. Solid-State Circuits Conf. Tech. Dig., Feb. 2002, pp. 348-349.

[9] O. Boric-Lubecke, G. Awater, and V. M. Lubecke, "Wireless LAN PC Card Sensing of Vital Signs," IEEE Topical Conference on Wireless Communication Technology (2003), pp. 206-207.

[10] Y. Xiao, J. Lin, O. Boric-Lubecke, and V. M. Lubecke, "A Ka-band low power Doppler radar system for remote detection of cardiopulmonary motion," presented at the 27th IEEE Annu. Eng. Med. Biol. Soc. Conf., Sep. 1-4, 2005.

[11] C. Gu, C. Li, J. Lin, J. Long, J. Huangfu, and L. Ran, "Instrument-Based Noncontact Doppler Radar Vital Sign Detection System Using Heterodyne Digital Quadrature Demodulation Architecture," IEEE Transactions on Instrumentation and Measurement, Vol. 59, No. 6, pp. 15801588, June 2010.

[12] V. M. Lubecke, O. B. Lubecke, A. H. Madsen, and A. E. Fathy, "Through-the-wall radar life detection and monitoring," in IEEE International Microwave Symposium, 2007, pp. 769-772.

[13] C. Li and J. Lin, "Random body movement cancellation in doppler radar vital sign detection," IEEE Trans. on Microw. Theory Techn., vol. 56, pp. 3143-3152, 2008.

[14] I. V. Mikhelson, S. Bakhtiari, T. W. Elmer, and A. V. Sahakian, "Remote sensing of heart rate and patterns of respiration on a stationary subject using $94-\mathrm{GHz}$ millimeterwave interferometry," IEEE Transactions on Biomedical Engineering, Vol. 58, Issue 6, pp. 1671 - 1677, 2011.

[15] D. Obeid, S. Sadek, G. Zaharia, and G. El Zein, "NonContact Heartbeat Detection at 2.4, 5.8 and $60 \mathrm{GHz}$ : A Comparative Study," Microwave Opt. Technol. Lett., vol. 51, no. 3, pp. 666-669, March 2009.

[16] D. Obeid, S. Sadek, G. Zaharia, and G. El Zein, "Multitunable Microwave System for Touchless Heartbeat Detection and Heart Rate Variability Extraction," Microwave Opt. Technol. Lett., vol. 52, no. 1, pp. 192-198, Jan. 2010.

[17] D. Obeid, S. Sadek, G. Zaharia, and G. El Zein, "Low Power Microwave Systems for Heartbeat Rate Detection at 2.4, 5.8, 10 and $16 \mathrm{GHz}$, Proc. of the International Conference on Applied Sciences in Biomedical and Communication Technologies, ISABEL 2008, Aalborg, Denmark, October 2528, 2008.

[18] P. Joseph, U. R. Acharya, C. K. Poo, J. Chee, L. C. Min, S. $\mathrm{S}$. Iyengar, and H. Wei, "Effect of reflexological stimulation on heart rate variability," ITBM-RBM, vol. 25 , pp. 40-45, 2004 